\title{
Inquiry-based learning and digital storytelling in virtual exchange: an approach for reflecting on food consumption in the Global South and Global North
}

\author{
Silke Bartsch', Pisavanh Kittirath ${ }^{2}$, Heike Müller ${ }^{3}$, and Chandokkham Youyabouth ${ }^{4}$
}

Abstract

V irtual Exchange (VE) in higher education provides an underemployed opportunity for fostering consumer and sustainability competencies. We explore how a crosscultural teaching-learning environment can be designed to encourage students to reflect on a complex global challenge - food consumption patterns - and their role in it. We discuss challenges regarding food consumption as a topic for VE and describe a didactic concept that employs inquiry-based learning and digital storytelling as the framework for student exploration and expression. Initially developed for VE in food studies and nutrition education, the concept can be readily transferred to other disciplines and topics. We present insights from a pilot implementation with 16 food science students from Laos and 26 pre-service teachers from Germany. The analysis of students' responses from preand post-questionnaires and their digital stories suggest that the concept is promising, although some factors require improvement and careful attention, such as technologies and the lingua franca of the learning environment. Findings and lessons learned might inform other projects that similarly seek to address complex global challenges.

\footnotetext{
1. Technische Universität Berlin, Germany; silke.bartsch@tu-berlin.de; https://orcid.org/0000-0001-5898-0943

2. Savannakhet University, Lao PDR; Pisavanhktr@gmail.com; https://orcid.org/0000-0003-4592-412X

3. Technische Universität Berlin, Germany; heike.mueller.2@tu-berlin.de; https://orcid.org/0000-0002-7394-1878

4. Savannakhet University, Lao PDR; ybouth@yahoo.com; https://orcid.org/0000-0002-7349-6858
}

How to cite this article: Bartsch, S., Kittirath, P., Müller, H., Youyabouth, C. (2021). Inquiry-based learning and digital storytelling in virtual exchange: an approach for reflecting on food consumption in the Global South and Global North. Journal of Virtual Exchange, 4(SI-IVEC2020), 47-69. https://doi.org/10.21827/jve.4.37152 
Keywords: nutrition and consumer education; food science; inquiry-based learning; digital storytelling; UN sustainable development goals.

\section{Introduction}

Food consumption is an important area of sustainable development. How we eat is either directly or indirectly related to global challenges such as the world hunger crisis, soil degradation, food waste, packaging, and the consequences of adopting Western diets in the Global South (von Koerber, Waldenmaier, \& Cartsburg, 2020; Willett et al., 2019). To address the complex and interrelated challenges, the EAT-Lancet Commission advocates for a "Great Food Transformation" as the "unprecedented range of actions taken by all food system sectors across all levels that aim to normalize healthy diets from sustainable food systems" (Willett et al., 2019, p. 450, emphasis added). As one of the levels, education has an important role to play in contributing to this transformation.

In the context of higher education for sustainable development, we thus pursue the question: how can a teaching-learning environment be designed to encourage students to reflect on their (un-) sustainable food consumption patterns? Here we put forward one approach and offer a starting point for further developments.

We refer to sustainable consumption behavior as "individual acts of satisfying needs in different areas of life by acquiring, using, and disposing [of] goods and services that do not compromise the ecological and socio-economic conditions of all people (currently living or in the future) to satisfy their own needs" (Geiger, Fischer, \& Schrader, 2017, p. 20). Behavior patterns in private households are particularly interesting. For instance, habituated decisions around food consumption are efficient for handling daily life because they are quasi-automatic and are rarely questioned. Consumption patterns mirror the respective production and provision systems available to the consumer (Reisch et al., 2020).

UN (2015) Sustainable Development Goal (SDG) 12 integrates both sustainable consumption and production. The concept of "sustainable nutrition" (von Koerber et al., 2020, p. 38) provides a basis for reflecting on the extent of sustainability in everyday food patterns. It includes all the steps in the value chain (sourcing, production, marketing, transportations, storage, processing, procurement, at home preparation, disposal). Further, the concept considers five dimensions: the 
three pillars of sustainability (environment, economics, society) as well as health and culture (von Koerber et al., 2020).

We focus on an opportunity for approaching the global challenge of (un-)sustainable food consumption in education through a cross-cultural exchange mediated by digital technology. Although cooperation between VE partners in the so-called Global South and North is widely regarded as desirable, South-North collaborations in VE are still comparatively rare. We discuss insights gained from a VE project between partners in the Global North and South on the topic of private household food consumption. First, we embed the work in a theoretical framework of nutrition and consumer education. Based on this, we present a didactic concept that combines inquiry-based learning and digital storytelling (the FETA approach) in a VE. In a pilot seminar, we tested the approach with students from Germany and Laos. Using analyses of a pre- and postpilot questionnaire and digital stories created by the students, we examined the potentials and challenges of the approach. This exploration is intended less to make generalized claims but more to support the maturing of the concept, and thereby contributing to the field. Thus, our aim is to enhance the discourse regarding the use of VE on food consumption patterns in the context of education for sustainable development.

\section{Between food and nutrition: everyday eating as a topic for VE}

People are generally interested in food because they can readily associate it with personal meaning. Food has been an attractive topic for VE - e.g. using recipes for language learning first and then 'cooking' accordingly (Gaer, 1995). Indeed, food works well as a topic for interdisciplinary learning, particularly when all of the disciplines involved provide well-crafted and highly relevant learning opportunities. From the perspective of nutrition and consumer education, however, it seems problematic to 'just' prepare food or share what we each had for breakfast. Such practices fall short of addressing the multifacetedness of food, such as its many dimensions (e.g. physical, cultural, political, biographical, social, sensorial, aesthetic, and technological), its areas of differentiation (e.g. social milieus, income levels, age groups, genders, city/urban dwellers), as well as the heterogenic aspects that people have in common vis-à-vis food (e.g. the diversity, variability, and indeterminacy of food, for instance, in biographical contexts or over lifespans) (Methfessel, 2005).

The EVOLVE Project team (2020) found that low-stakes conversations in VE led to superficial student interaction (e.g. when exchanging information on daily, material life, including food). Instead, "controversial topics, such as racism, religion, gender, or politics" seemed to encourage students to exchange worldviews or perspectives (EVOLVE Project team, 2020, p. 61). Is food thus an 
unsuitable topic for VE? On the contrary, its newly spurred global topicality stems precisely from its entanglement with such controversies. Further, it is not the topic alone that determines suitability for VE, but rather the overall design of the VE. We must seek to develop VE project designs that avoid simplistic or folkloric approaches to food while also aligning the projects with the goals of nutrition and consumer education.

Because people make daily decisions about what they eat, where, with whom, how and when, their habits and decisions have an impact on (un-)sustainable development. As the EAT-Lancet Commission points out, "[f]ood systems have the potential to nurture human health and support environmental sustainability; however, they are currently threatening both” (Willett et al., 2019, p. 447). Key issues, such as human health and environmental sustainability, have recently spurred new questions about, and assessments of, what people eat. The study of food in sociocultural contexts complements scientific considerations of nutrition, not least because it raises questions about the reasons for certain dietary patterns (Barlösius, 2016). Thus, aspects of both food and nutrition constitute the basis for reflecting on one's own consumption-related actions. This understanding seems especially important in education for sustainable development, which, for example, could strive to encourage action in the transformation of food systems.

On the one hand, global partnerships are important for achieving a "Great Food Transformation" (Willett et al., 2019, p. 450). In the context of nutrition and consumer education, this includes core elements of specialized professional development for teachers, such as recognizing diversity and leveraging it productively in the learning environment. This entails supporting students in learning to understand one's own food context as but one possibility, addressing the development of food cultures on different levels - individual, family, region, nation, etc. - and creating opportunities for recognizing that food systems are indeed changeable (Methfessel, 2006).

On the other hand, in the current debate on sustainable consumption and production, it sometimes seems less obvious just how central education is. The EAT-Lancet Commission stressed that "this transformation will not be achieved without people changing how they view and engage with food systems” (Willett et al., 2019, p. 450). Research carried out primarily in so-called developed countries suggests that regulatory or fiscal measures are more effective in creating sustained consumer behavioral change than 'soft' policies (e.g. information, advice, education) (Reisch et al., 2020; Willett et al., 2019). Nonetheless, education may have an impact on consumers' (and citizens') actions, attitudes, and intentions, which in turn could be reflected in frameworks, policies, and instruments of the global food systems. To this, Garnett, Mathewson, Angelides, and Borthwick (2015) propose that a greater consumer engagement "may instil in policy makers and the food industry the confidence to take more radical action as needed” (p. 82). 
At the center of modern food and consumer education (according to REVIS ${ }^{5}$ ) are acting persons and the development of individual and sociocultural resources. All VE participants can thus contribute to the dialog on food consumption and sustainable development. They too shape food systems and are in turn affected by them (e.g. in their personal health and social lives). For a VE about food consumption to be meaningful, we must invite students to engage beyond the superficial level of conversations, such as what we each had for breakfast or trading recipes. We propose that the first step must be observing one's own eating behavior. Specifically, we suggest that this be undertaken with a specific (research) question focus, such as How often do I eat fruits and vegetables?, and within the context of one's own eating environment and eating culture, such as What kind of fruits and vegetables do I find in the places where I can obtain food?. The results then can be reflected on, discussed, and addressed among the students, and checked against opportunities for sustainable development.

\section{Developing an approach for VE on food in global dimensions}

'Digital Food Stories' is a project at Technische Universität Berlin (TUB), Germany, and Savannakhet University (SKU), Laos, designed to facilitate students from the Global South and North engaging with one another to contribute to the SDGs (UN, 2015). Food is the thematic focus of the project, in part because of the relevance of this field to sustainable development and in part because it constitutes a mutual core interest of the study programs and instructors involved. Specifically, these are the Bachelor of Food Science at SKU as well as the Master of Education in work studies education at TUB.

The methodological approach is that of Educational Design Research (EDR) which synergistically addresses both theory and practice (McKenney \& Reeves, 2019). Theoretical understanding serves as the underpinning for the intervention design and for framing the research. Additionally, the theoretical understanding itself is advanced through empirical inquiry (McKenney \& Reeves, 2019). EDR thus aims to make both theoretical and practical contributions to the complex field of educational practice. It is important to note that the research findings presented here belong to the first research and design cycle of EDR and thus constitute the results of a first analysis, exploration, design, construction, implementation, evaluation, and reflection, which in further cycles might lead to a maturing intervention and deepened theoretical understanding.

5. The research project Reform der Ernährungs- und Verbraucherbildung in allgemeinbildenden Schulen (REVIS) framed educational goals and competencies and created an important basis for modern nutrition and consumer education in German-speaking countries (www.evb-online.de). 
During an initial analysis and exploration phase, based on a review of the literature and discussions among the project partners, we identified several problems at the intersection of food and consumer education and education for sustainable development.

- Everyday practices related to food in different countries are predominantly perceived as separate from one another. However, the conditions and consequences of food consumption in everyday life do not stop at national borders and affect (un-)sustainable development.

- Research into everyday foodways in young adult households is just beginning.

- Reflecting on one's own consumption patterns (including eating) is not a matter of course and must be learned. This also applies to the young adults in the project context (students), who will later work as multipliers in the field of food (i.e. as trained food specialists and as teachers) and act today within their respective contexts.

- Fostering sustainable consumption and production patterns is an urgent challenge of our time, requiring global collaboration.

- Internationalization and global cooperation are becoming an increasingly important focus for universities. Despite its importance, only a few students have the opportunity for international exchange, especially between the Global South and North.

In the subsequent construction and design phase, teaching approaches and lines of inquiry were studied, selected, and synthesized to meet these issues and pursue the project goal of collaboratively developing a teaching-learning environment to support our students in critically dealing with everyday food practices that may be more or less sustainable.

\section{The concepts of the FETA approach}

VE, inquiry-based learning, and digital storytelling are didactic approaches that are appropriate for complex challenges. In our first research and design cycle of EDR, these three approaches proved to be cross-fertilizing. In the synthesis, we developed the FETA concept.

FETA is an acronym in German that stands for forschend lernen (inquiry-based learning), erzählen (telling [digital stories]), virtuell ausTAuschen (VE) (Figure 1; Bartsch \& Müller, 2020). Figure 1 illustrates the basic idea of tying the three approaches together: students meet learners from another cultural and geographical context (e.g. the Global North or South) in the setting of a VE, where they develop research projects in the spirit of inquiry-based learning and use digital storytelling for communicating their subjective theories. Several variations are possible, depending on whether the students research in same-university teams that then meet with students from a partner course (e.g. 
teams that work on similar inquiry questions) or in cross-cultural teams that collaborate (e.g. two students from each country work on one shared question).

Figure 1. The FETA approach: inquiry-based learning with digital storytelling in VE

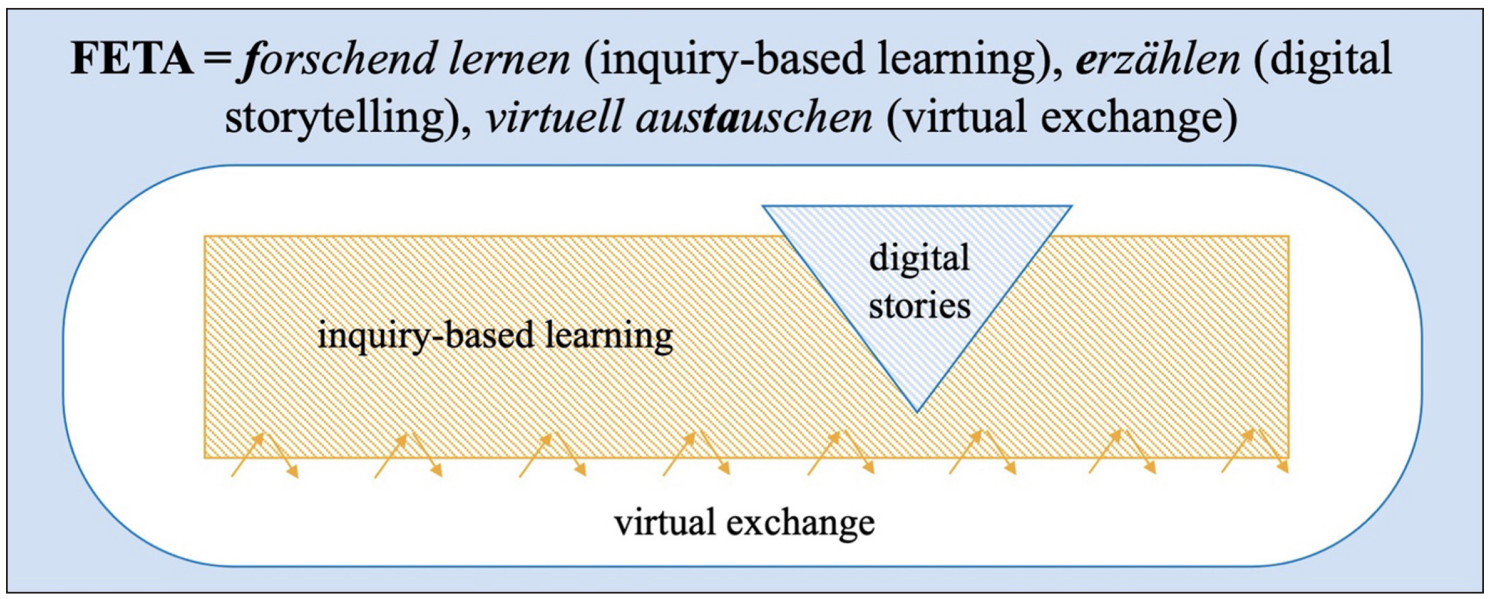

\subsection{Engaging in VE}

In VE, learners from different geographical places or cultural contexts meet in virtual spaces to interact (EVOLVE, n.d.; O'Dowd, 2018). What this interaction looks like and how the respective teaching-learning environment is designed are central questions (O'Dowd \& Waire, 2009). One of the criticisms of VE is that the discourses within VE all too often remain on a superficial level (Kramsch, 2014; O’Dowd, 2016), which forfeits the potential to explore culture from multidimensional perspectives and recognize its dynamism.

Supporting students in building knowledge and competencies for everyday household management is an explicit and inherent educational goal of nutrition and consumer education (Bartsch \& Methfessel, 2014b). This in turn helps learners to recognize the relevance for their lives more directly. Furthermore, thinking things through from perspectives of everyday life (such as subjective experiences, previous knowledge, everyday knowledge, or interests) challenges learners to look at individual and collective actions and behaviors from multiple perspectives (Bartsch \& Methfessel, 2014a). This becomes illuminated in answering the question What do 'we' eat (and what not)?. To avoid the danger of forming or relying on stereotypes by hastily assigning individual processes to 'culture', thus losing sight of the individual, we must structure the learning experience to intentionally 'unpack' our food consumption patterns. To this end, linking discussions about food 
consumption from an everyday perspective with the scientific discourses on food and nutrition is key. Such a discourse requires questioning and discussing backgrounds and implicit attitudes on food consumption and production, including dimensions such as the social, political, economic, biographical, religious/cultic, ethical, historical, technological, aesthetic-culinary, physical, sensory, etc. (Methfessel, 2005).

The FETA approach, therefore, uses inquiry-based learning as the angle from which to address the complex topic of food consumption. Inquiry-based learning here aspires to engage the students in a discovery process regarding a matter that at first may appear banal. Students connect via VE to develop small research projects, implement them, and exchange ideas. The aim is to support the students in developing a reflective approach to their own everyday experiences, to be able to describe and compare everyday practices of the peer group based on (cultural) scientific theories, and to evaluate them in terms of sustainable consumption. This includes being able to question one's own everyday practices, acknowledge one's embeddedness in the surrounding culture, and recognize that culture is ever-evolving and can be changed (Methfessel \& Schön, 2014). The VE provides a setting in which the chosen topics and the insights gained are of interest not only to the students themselves, but also to third parties (a core tenet of inquiry-based learning). Moreover, VE makes it possible to conduct research together in cross-cultural student teams or - with sameuniversity teams - to discuss emerging challenges and questions in a cross-cultural setting.

The most challenging aspect and the culmination of the VE is the discussion of, and collaborative development of, possibilities for (more) sustainable food consumption. The VE setting facilitates ways to raise questions of global relevance, to discover local opportunities for tackling common global challenges, and to build competencies, relevant knowledge, skills, and mindsets. However, the challenge of addressing unsustainable food consumption is complex, and responsibility for it is shared. As the EAT-Lancet Commission stresses, "no single actor or breakthrough is likely to catalyse systems change” (Willett et al., 2019, p. 448). One single VE project will not likely lead to the one solution. But it may be one part of achieving this Great Transformation.

\subsection{Learning through research and inquiry}

Inquiry-based learning can be defined as an educational strategy and a form of learning in which learners foremost (co-)design, experience, and reflect on the essential phases of a research project (Pedaste et al., 2015). In doing research themselves, the students can acquire knowledge of - and experience in - their discipline ("learning through research", "learning from research", and "learning about research", Dekker \& Walsarie Wolff, 2016, p. 2). The process begins with an "orientation" (Pedaste et al., 2015, p. 52), in which the instructors introduce themes and theories 
and support students in finding their bearings in the scientific discourse ${ }^{6}$. Questions or hypotheses mark the next step. These are generated and chosen by the students themselves, but are geared toward findings that are of interest to third parties also (Huber \& Reinmann, 2019). The activities that the students then undertake in their investigation depends on their understanding of their respective discipline as an academic one (e.g. a field worthy of study), their awareness of the ideals for knowledge creation (epistemic ideals) in the discipline, and the extent to which they are familiar with the spectrum of research methods and types in common use in the discipline (Huber \& Reinmann, 2019). In conceptualizing their inquiry, the students select paths and tools (methods) that lead to meaningful answers (research design). Discussion and reflection mark the end of the process (Pedaste et al., 2015).

Profound knowledge is a necessary part of developing the competence to critically analyze and reflect on food consumption. However, drawing conclusions, dealing with potentially contradictory developments, and possibly polarizing discussion, taking responsibility, and discovering and implementing new options for action (Bartsch \& Methfessel, 2014a) all require making connections with one’s everyday life and its subjective meanings (Bartsch \& Müller, 2020). This is where digital storytelling comes in.

\subsection{Digital storytelling as a means for expressing personal meaning}

Storytelling is a seasoned method for narrative transfer of knowledge. In digital storytelling in educational contexts, the learners create "a short movie by combining digital artifacts such as images, text, video clips, animation, and music using a computer-based program” (Robin \& McNeil, 2019, p. 1). Typically, audio narration enriches the videos and provides an emotional element. Sharing the stories is a crucial part of the process as digital storytelling can be about supporting individuals in finding their voices and providing a medium through which they can tell their stories. In the FETA approach, the students compare their findings from inquiry-based learning with their own life stories (e.g. by linking published findings with their own research results and their biographical experiences in the digital stories). The experts regarding what food means in their lives and contexts for personal action are the students themselves (Bartsch \& Methfessel, 2014b). They are the ones who know the experiences, feelings, and values they associate with food.

Digital storytelling can help to relate the 'academic knowledge' from inquiry-based learning to one's own everyday lifeworld and, in VE, to focus 'fuzzy' interests in the partners' lifeworld. It

6. When embedding inquiry-based learning in VE, learners should already have basic knowledge of research methods and techniques (e.g. from introductory courses) in order to avoid overwhelming them. Furthermore, it is advisable to define a common research focus that all students will engage in. In the pilot we chose 'food management in everyday life in student households'. 
provides a format for the exchange while creating clarity about the expectations. As 'exchange products', digital stories might further help to break down language barriers through asynchronous sharing. Additionally, students can view the stories multiple times. The digital stories can also be used to prepare for a synchronous meeting via a professionally guided and reflective exchange of experiences. The aim here is to support students in dealing with research in a way that is biographically relevant. Then, as potential multipliers, they can contribute to the link between research and society.

The FETA approach is the result of an initial phase of exploration and analysis. The EDR cycle continues with design, implementation, reflection, and evaluation. As part of the first EDR cycle within the project, we examined the potentials and challenges of the approach by means of a pilot implementation, supported by research on (1) student satisfaction, (2) potential and perceived benefits, and (3) insights from their digital stories.

\section{Insights from a pilot implementation}

\subsection{Method}

Forty-two students participated in the pilot implementation. The group consisted of 26 pre-service teachers in work studies education at TUB and 16 food science students in four different majors at SKU (Table 1). Sustainability is a guiding perspective in all the participating degree programs.

The objectives of the course within the program at TUB included:

- developing and applying interdisciplinary competencies, especially project managing competencies;

- applying their knowledge to scientific work in subject-related student research projects under supervision, thereby expanding their repertoire of research methods; and

- deriving and discussing questions for their final theses.

The objectives for the students at SKU included:

- applying their knowledge to daily food consumption;

- developing their skills in explaining what they need to prepare food; and

- developing subject-related knowledge on and competencies in intercultural communication. 
Table 1. Overview of student participants and their study contexts

\begin{tabular}{|l|l|l|}
\hline Institution & SKU & TUB \\
\hline Courses involved & $\begin{array}{l}\text { Undergraduate research, } \\
\text { course independent }\end{array}$ & $\begin{array}{l}\text { Subject-matter research on teaching } \\
\text { and learning (pre-service teachers) }\end{array}$ \\
\hline Number of students & 16 students & 26 students \\
\hline $\begin{array}{l}\text { Degree programs and } \\
\text { majors of the students }\end{array}$ & $\begin{array}{l}\text { Bachelor of Food Science: } \\
\text { • Agribusiness and Marketing } \\
\text { • Food Processing Technology } \\
\text { • Post-Harvest Technology } \\
\text { and Product Promotion } \\
\text { • Economics for Rural Development } \\
\text { and Business Extension - } \\
\text { International Course }\end{array}$ & \\
\hline
\end{tabular}

We selected household food management as the topic for inquiry-based learning and embedded this into our courses by means of readings and discussion. Sustainability was introduced later via discussions in our respective class sessions. The course design was based on the FETA approach (see above) and the Progressive Exchange model (O'Dowd \& Waire, 2009; The EVALUATE Group, 2019). Accordingly, the students received three interrelated tasks derived from the three phases of the Progressive Exchange model: information exchange, compare and analyze cultural practices, and work on a collaborative product (Figure 2). However, due to disruptions related to the COVID-19 pandemic, the students were only able to complete the first two tasks while the third task of global collaboration on a product was mostly uncompleted.

In the beginning of the VE project, the students created videos and posters to introduce themselves (Task 1). We also asked the students to complete an online questionnaire that included open-ended questions for describing their cultural backgrounds and their hopes regarding achievements or learning outcomes from the VE. Those students with the means to work from home (during the COVID-19 semester interruption) then collected and shared questions about their partners' everyday food management. Instead of cross-cultural groups, we formed same-university teams. The teams then turned some of the questions from the partners into inquiry projects on their own food consumption. Subsequently, the students created digital stories about their insights ${ }^{7}$.

7. We did not require the students to address sustainability at this stage. Rather, we intended to use the students' work as a starting point for collaboration on sustainable consumption as a final step in the VE. 
Each teams' work was shared with the other teams. Students then discussed the topic in terms of sustainable consumption in a final video conference that included all students from both countries. Not all teams were able to complete their inquiries and create a digital story. Thus, we improvised and used three digital stories that student groups from SKU created in prior iterations of this project.

In a second online questionnaire at the end of the VE, we asked the students to (1) describe their experience by writing approximately 300 words, (2) rate their satisfaction with the course and with the virtual exchange each on a 7-level Kunin scale, (3) rank the activities conducted from best to worst, (4) evaluate five statements on the outcomes on a 5-level Likert scale, and (5) comment on their answers and answer two open-ended questions on their experiences and possibilities for improvement.

Figure 2. Tasks in the VE model (adapted from O'Dowd \& Waire, 2009; The EVALUATE Group, 2019)

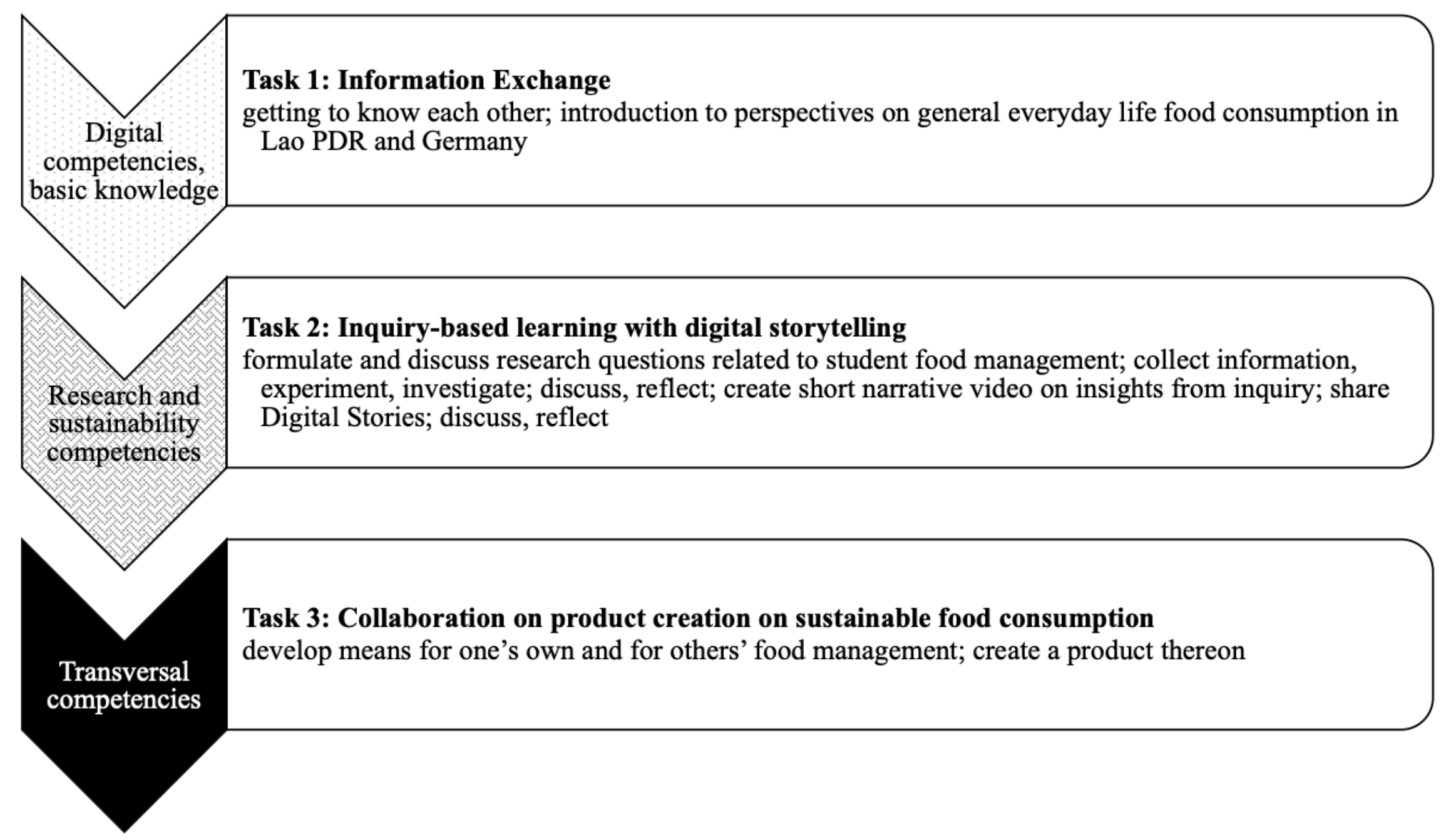

\subsection{Data analysis and limitations}

To investigate the potentials and challenges of the approach, we analyzed the (anonymized) students' responses to the pre- and post-experience questionnaires as well as the seven digital stories from 
the students in Germany. Our questionnaire analysis included a total of 59 completed responses: 37 from the pre-test and 22 from the post-test (response rate of $81 \%$ in the pre- and $52 \%$ in the post-test questionnaire) ${ }^{8}$.

To analyze quantitative data from the questionnaires, we used descriptive statistics. We employed a content analysis approach for the qualitative data. For the latter, two people independently coded the students' responses to pre-VE hopes using the 4Cs (content, communication, cognition, and culture) from the 4C framework (Coyle, 2008) as deductive categories. For the post-VE qualitative data, one of the previous coders and another coder independently allocated the following codes: positive or negative aspects of the experience, perceived factual benefits (excluding those addressed as potential benefits), influencing factors, and aspects for improvement.

We also chose a content analysis approach for exploring the digital stories. We analyzed the latest digital stories that students created within the pilot, resulting in a total of seven videos, from Germany only. The three supplemental digital stories from Laos (see above) originated from prepilot phases in 2018 and 2019. As inquiry-based learning was not yet integrated during that time, we excluded these from our analysis. After the VE project, two coders independently coded the digital stories, according to a semi-structured guide, on whether the videos contained cues on students reflecting on their everyday life food management and on what sustainable consumption means in the students' perspectives.

In both cases (qualitative data from the questionnaires and from the digital stories) two researchers discussed inconsistent coding results until they reached consensus.

\subsection{Findings and discussion}

\subsubsection{Hoped for and perceived benefits}

When asked about hopes for what they might achieve or learn from this VE beforehand, the students most prominently expressed hope to learn more about 'culture' (e.g. about cultures in general or learning cultures). The mention of 'eating culture' particularly demonstrates the close connection between culture and content on the topic of food consumption. For example, student 208 expressed his interest: "I want to know the German eating culture, how many [sic.] they eat per day? What kind of food do they consume for breakfast?”.

8. As the structures of the programs and courses place students in a power imbalance with their instructors, we only encouraged the students to participate but did not insist on it. Accordingly, the results of the questionnaire are subject to self-selection bias. 
In the grounding for our study, we highlighted the importance of discovering and considering the tension between individual and culture when dealing with food as a topic. Both in the analysis of the students' digital stories (see below) and in the description of a student's experience with the project from the post-questionnaire, we found indications that some students started to differentiate these:

"The task was to investigate research questions concerning our everyday nutrition - in particular our everyday life as students. As a group, we quickly realized that although we are all students, we still live in very different life situations. We turned this into a research assignment” [57].

In the students' hopes before the experience began, communication was mainly connected to English as a foreign language, e.g. "I want to learn more English" [195]. After the exchange, some students did mention appreciating the opportunity to practice or improve their English. Others, however, found the lack of competence in the lingua franca more of a barrier (e.g. "it was very difficult to understand the [partner] students” [69]).

In the pre-experience questionnaire, some students mentioned digital communication as a potential benefit. In the implementation, digital communication was connected to several challenges, such as different systems for learning management, for communicating, or divergent ideas about data protection. Following the VE, the most frequently mentioned point for improvement was 'internet' - both access and stability.

When the classroom internet connection for videoconferences failed or when synchronous VE was impossible for students with little means to work from home during local lockdowns, digital storytelling was particularly useful, as the stories served as 'exchange products'. In the post-pilot questionnaire, students commented on appreciating how the stories can be used as artifacts in other contexts, "I did like to present our results with the digital story. It is more presentable than a paper. The video is a result, which I even can show my parents or other people” [84]. Nevertheless, in a ranking of the activities performed, the students liked other activities better: class input and discussion were ranked as best, followed by collecting potential research questions and designing their own research.

Prior to the VE, some students wished to learn in 'a different way', (e.g. to learn from one another [140]) and to foster thinking "outside the box" [146]). One student wrote: "I think learning from actual people will help me to keep the things I learned in mind, rather than reading it somewhere without real connection to it" [188]. A few students even hoped to make new friends. Both were fulfilled for some students, as these examples illustrate: 
"I learned a lot. It was helpful to go through the processes of inquiry-based learning and digital storytelling by myself. The experience makes it much more likely to run a similar project in class” [80 - a pre-service teacher].

"I am so happy who [sic.] participated in this event. Because it has made you acquire knowledge and experience and get to know more friends than ever before” [129].

The majority (73.7\%) of the students participating in the post-pilot questionnaire indicated that they 'learned a lot from the virtual exchange', with an average of 3.79 out of 5 (Figure 3). Some found the VE useful for their 'future career' $(68.4 \%, 3.74)$ and for their individual 'food management’ (57.9\%, 3.53).

Figure 3. Satisfaction with the VE (1=totally disagree, 2=disagree, 3=neither disagree/nor agree, 4=agree, 5=totally agree)

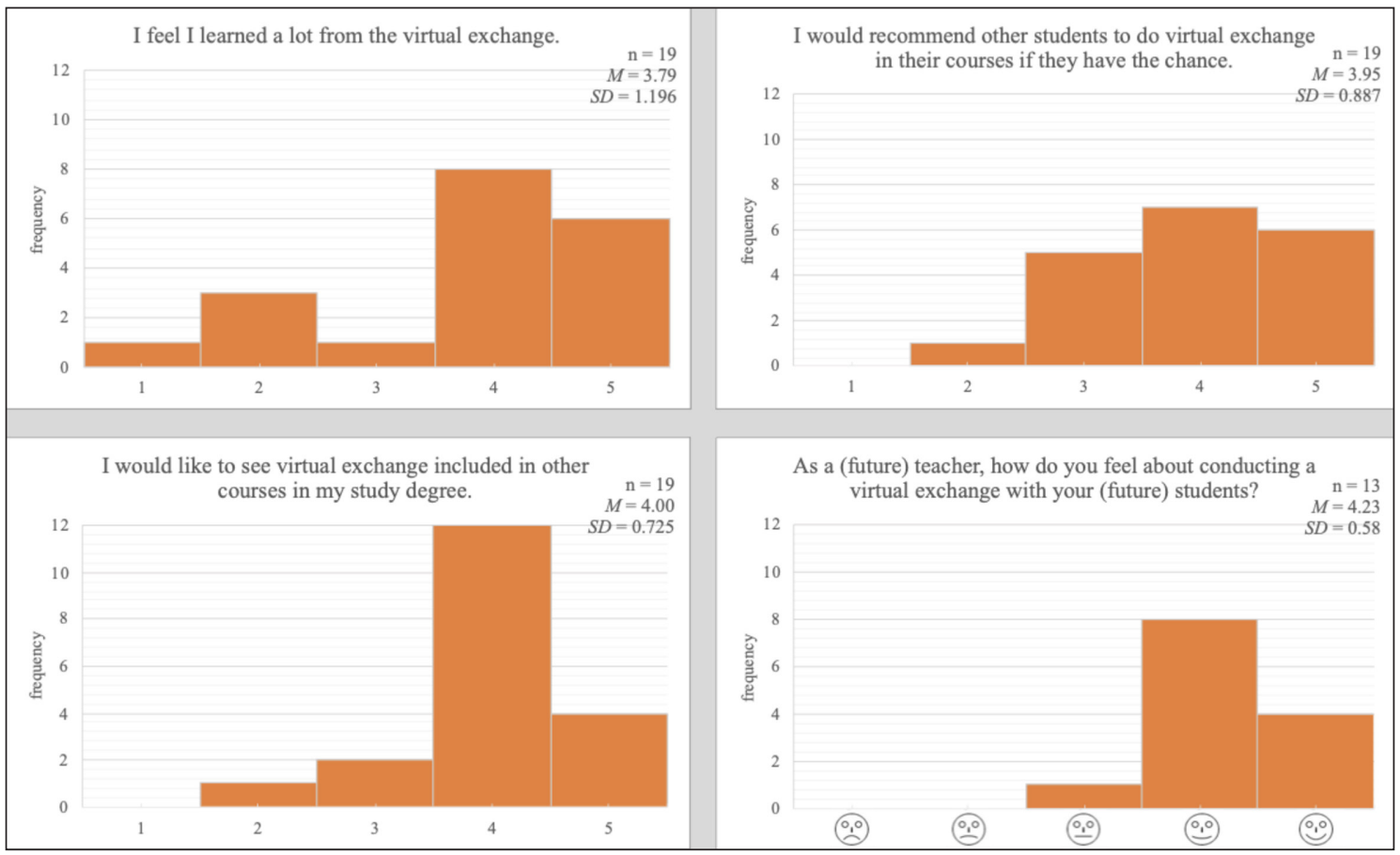

Thirteen participants identified themselves as future teachers (from both universities). Upon being asked how they 'feel about conducting a VE with [their] (future) students' on a 5-level Kunin scale, $52.6 \%$ of them chose a slightly smiling and $31.6 \%$ a big smiling face (Figure 3). Moreover, many of the 
students would 'recommend other students to do VE in their courses if they have the chance' (68.4\%, 3.95). Even more would like to see VE 'included in other courses' in their respective degree programs $(84.3 \%, 4.00)$. Although this data is limited for the reasons outlined, when paired with the findings of the qualitative data, it does help to shed light on the students' impressions.

\subsubsection{Student satisfaction with the pilot}

Overall, the participants reported being satisfied, although more so with the courses (average of 5.75) than with the VE (5.31), as indicated by a slighter higher mean and a lower standard deviation (Figure 4). All participating students from Laos, but only some from Germany, expressed satisfaction with the VE. On the one hand, this is suggested by the distribution of the quantitative rating on satisfaction (Figure 5). On the other hand, the qualitative data sheds some more light on these findings. Neither offer a complete explanation of this stark difference, which also might be culturally situated or related to the difficulty for students in Germany in reaching students in Laos during the interruption of classroom-based teaching with the consequence of not being able to communicate with students lacking the means to work from home, etc.

\section{Figure 4. Overall satisfaction with the course and with the VE}

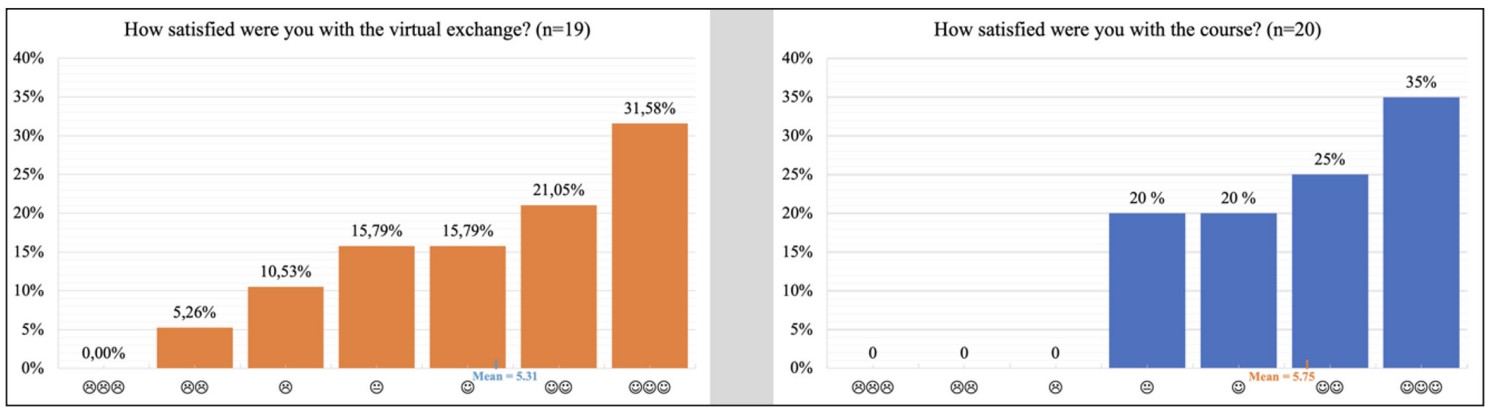

Regarding satisfaction with the VE, the comments with the largest deviations on the Kunin scale are particularly interesting. Two of the three students who chose frowning faces provided comments reasoning that the VE "was fun and interesting, but the communication was not good!" [69] or that "because of the Corona crisis, there was no exchange" [57]. Satisfied students wrote, for example: "I am very happy to be a part of this program" [106] or "it is advisable to proceed with the project" [129]. The larger body of positive comments suggest that, for most students, participating in the pilot was a motivating experience. Limited time, the comparatively high workload, and the aggravated life situation during the pandemic seem to have had a negative impact on the satisfaction of some 
students. Also, some students would like to have more opportunities for exchanging with each other (e.g. in more VE sessions, smaller groups, or through physical mobility).

Figure 5. Satisfaction distributed by study place, gender, and year of birth

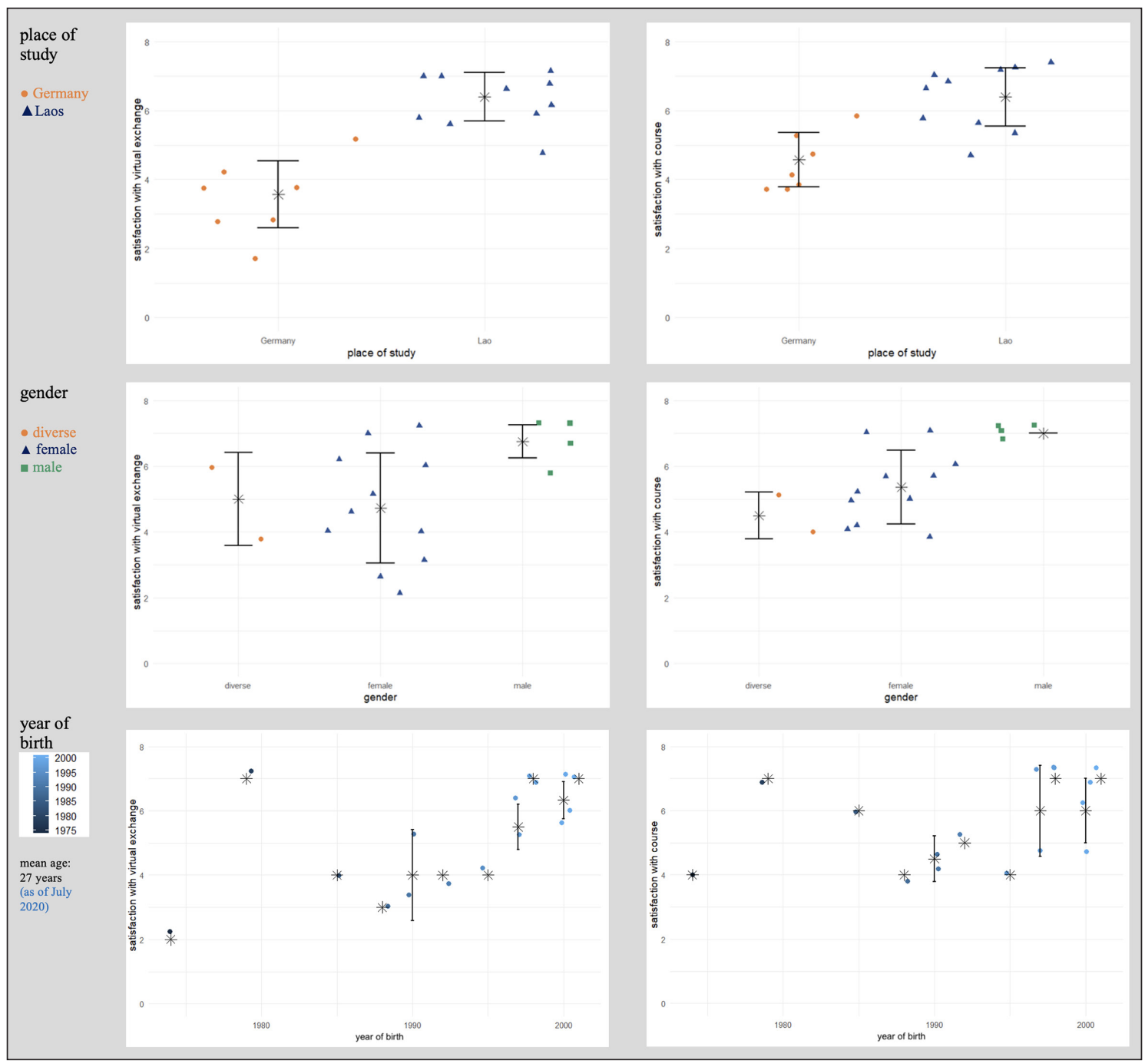

The suggestion that employing inquiry-based learning and digital storytelling in a VE is a productive approach is supported by statements such as this one: 
"The seminar was a totally new experience to me. Not only digital/virtual exchange but also the way we gained and edited the data. In the beginning it was hard to come up with questions because the topic was everywhere in the daily routine and I had to think about it in a distance. I learned that producing a digital story is possible without special technical devices. But still it took more time than expected" [80].

\subsubsection{Insights from students' digital stories}

All the stories analyzed showed evidence of students reflecting on their food consumption. For instance, one team examined the similarities and differences in eating patterns within their peer group and compared their findings to published research. As a poignant example, they discuss perceived time pressure as an influencing factor on decisions (e.g. what students eat, when, and how during exam periods). The team also linked further questions to this (e.g. the number of main meals and snacks, mindfulness or preoccupation during intake, the convenience level of the meals, habits and rituals shaping one's own eating behavior). These touch all five dimensions of sustainable nutrition: the individual/health, social, environmental, cultural, and economic (von Koerber et al., 2020). Despite this implicit link, the students did not explicitly address sustainable consumption.

Most of the stories, however, do contain cues on what sustainable food consumption means from the students' perspectives. For example, another group shared its insights from exploring students' rationales for wasting food by choosing a different approach. At the beginning of their digital story, they provided information on the amounts of food waste in Germany and the role of private households. They presented the fictional case example of 25-year-old Karl who studies at their university (Figure 6).

While watching his favorite TV series, Karl gets a craving for certain foods from the commercials. When he goes grocery shopping in the supermarket, Karl buys more than intended. Back at home, while putting away the food, he starts disposing of other foods for various reasons. The audio narrator exclaims 'Stop!', then asks how 'we' could help Karl to better shop for food and waste less.

As indicated in the screenshots from the digital story (Figure 6, bottom right quadrant) the students suggest specific consumption skills for reducing food waste. This is one angle for strengthening sustainable consumption (Reisch et al., 2020, p. 6). Despite the lower effectiveness of education as a 'soft' policy for behavior change as compared to 'hard' policies (e.g. regulation, standards, and financial incentives and disincentives) (see Chapter 2), the EAT-Lancet Commission proposes to make use of education campaigns, particularly for highly developed countries where the public is responsible for a large proportion of food waste: "[t]he Commission envisages use of campaigns to 
promote improved planning of purchases, understanding of best before and use by labels, storage practices, assessment of portions needed, food preparation techniques, and knowledge of how to use leftovers" (Willett et al., 2019, p. 482). The suggestions made by the students in their digital story almost entirely coincide with this list from the commission. Further, the scenario involving the television commercial raises points for discussion, e.g. on "renewed efforts by governments, industry, and society [...] to restrict advertising and marketing of unhealthy, unsustainable foods, and to support positive discrimination of healthy diets from sustainable food systems” across the globe (Willett et al., 2019, p. 480).

Figure 6. Scenes from a group's digital story on food waste

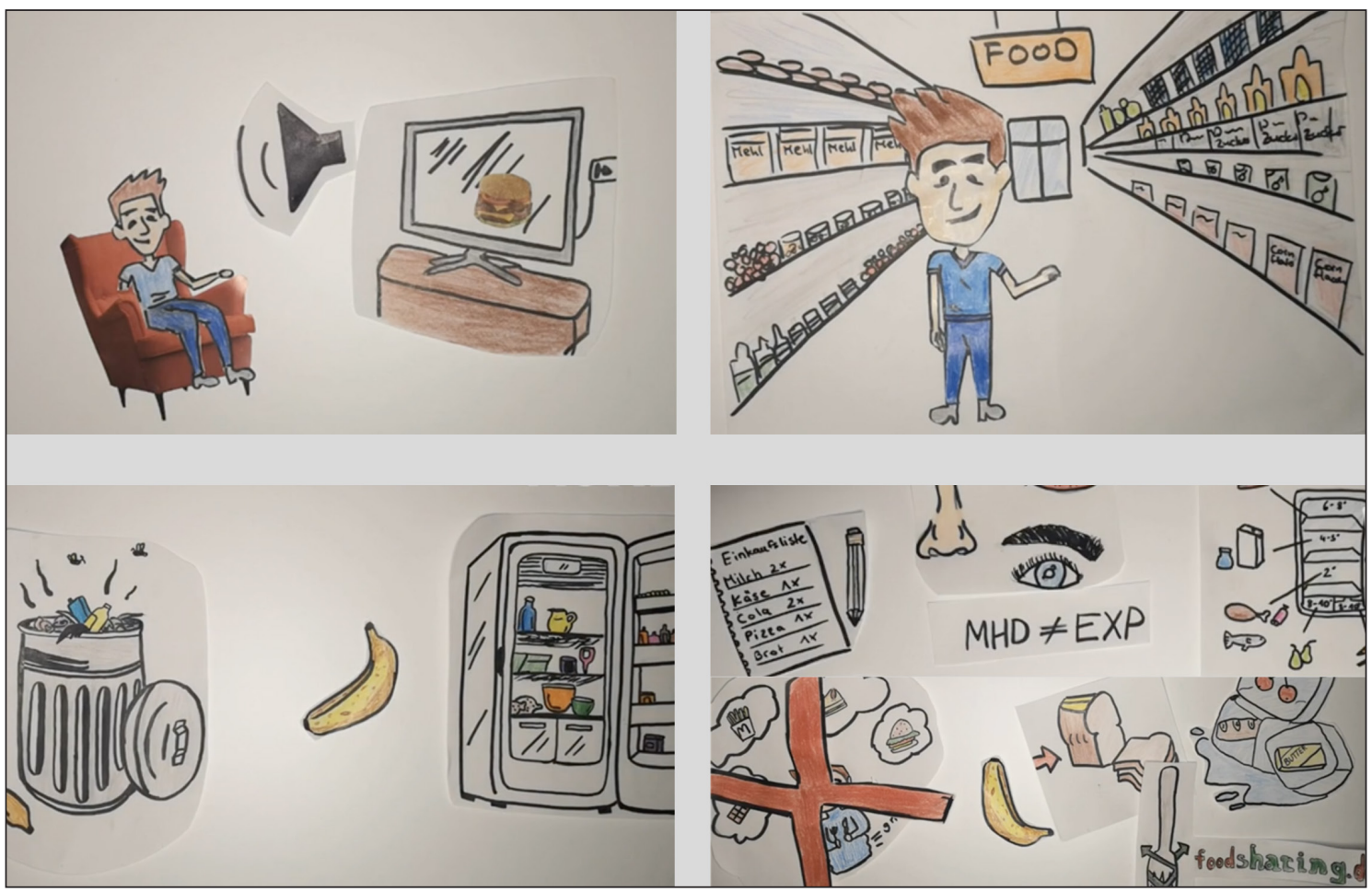

\section{Conclusion and implications for future research and practice}

We have explored the ways in which a teaching-learning environment can be designed to encourage students in the Global North and South to reflect on their food consumption patterns. The results 
suggest that integrating inquiry-based learning and digital storytelling into VE is a suitable way to provide students with opportunities to build consumer and sustainability competencies. Likewise, we argue that although food consumption seems an 'at hand' topic for VE, instructors need to be careful not to fall into the trap of simplification. We thus perceive vast potential for nutrition and consumer education that, to our knowledge, has so far gone widely untapped within VE project designs.

The FETA approach codifies the combining of inquiry-based learning with digital storytelling in VE. While the study of a pilot implementation has several limitations (sample size, self-selection bias, groups from Master's and from Bachelor's degrees, etc.), the findings are useful for gaining an initial picture and for advancing the intervention, and thus continuing with the next research and design cycles in the 'Digital Food Stories' project. Adding to the points previously raised, for further maturing the concept it seems essential to evaluate student learning outcomes.

For an initial picture, the analysis of students' digital stories indicate that the students reflected on their food consumption. Further, the findings from the students' pre-pilot questionnaire answers suggest that the concept was motivating, and the students' post-experience answers confirm that the VE was mostly successful. While, for most of the students, their hopes were largely met, there are several points for improvement. At that, our results underline some common findings from the VE literature. Together with insights from the design process, some key lessons emerged which might inform similar projects.

- While VE is often used in language learning, our project was theme-based. In a lingua franca VE setting, however, aspects of content, communication, culture, and learning (Coyle, 2008) are interrelated. Thus, finding ways to integrate these better (especially language learning in subject-matter classrooms and subject-matter learning in language classrooms) seems necessary from a perspective of nutrition and consumer education.

- In our pilot project, the issue of food management in everyday life was considered first. We intended to make this the starting point for a more in-depth discussion of and collaboration on sustainable consumption later. With the unforeseen events and continuous adjustments, the students and instructors did at times discuss sustainability, but in the North-South constellation only in one final videoconference. Making sustainability a guiding thread from the very beginning seems more advisable. This also ties back to installing more crosscultural touchpoints - after all, cross-cultural collaboration is the point of VE (Hauck, 2020).

- Against the upsides of learning with digital means, the COVID-19 pandemic has highlighted some downsides, especially with regards to students who do not have (reliable) at-home access to internet and devices. Solving internet-related problems for the learners involved 
on and off campus would help, but is by no means enough. As Hauck $(2019,2020)$ has pointed out: VE is not exempt from the risk of cementing social and cultural inequalities offline and online.

- The FETA approach is demanding. Thus, as has been pointed out before (Guth, Helm, \& O’Dowd, 2014; Helm, 2015), gaps in credit and recognition for students and instructors need to be resolved. On a course level, refining the task design(s) by setting smaller foci or further supporting the students might help (O’Dowd \& Waire, 2009). Involving students with prior knowledge of research methods or inquiry-based learning, as well as digital storytelling or even creating a video is advantageous.

- On a strategic level, the gaps need to be addressed at institute and university levels (UNICollaboration, 2014). This is especially true in the domain of education for sustainable development, as global challenges require global collaboration and physical mobility cannot be the prime choice because of its environmental impact. We thus argue, too, that a more systematic integration of VE into higher education seems appropriate.

\section{Acknowledgments}

We would like to thank all the students for their participation in the project. We kindly thank Carine Ullom and the reviewers for the Journal of Virtual Exchange for the valuable feedback on our manuscript. We are indebted to our colleagues Maninouth Phothirhath and Oudonexay Douangdala for their contributions to the project. We thank our student assistants Christin Herrmann, Tino Rothämel, and Sandra Kuriata for their support. The project 'Digital Food Stories' is currently not funded. However, its initiation was only possible through TUB seed funding and through the DAAD fact-finding mission program, for which we are truly grateful.

\section{References}

Barlösius, E. (2016). Soziologie des Essens. Eine sozial-und kulturwissenschaftliche Einführung in die Ernährungsforschung (3rd ed.). Juventa.

Bartsch, S., \& Methfessel, B. (2014a). Ernährungskompetenz in einer globalisierten (Ess-) Welt. Herausforderungen und Erfordernisse. Ernährung im Fokus, 16(03-04), 68-73. https://www.bzfe.de/_data/files/leseprobe_5682_2016_eif.pdf

Bartsch, S., \& Methfessel, B. (2014b). „Der subjektive Faktor“. Bildung in einem lebensweltorientierten Fach. Haushalt in Bildung \& Forschung, 3(3), 3-32. https://doi.org/10.3224/hibifo.v3i3.16665

Bartsch, S., \& Müller, H. (2020). Digitale Essgeschichten: Forschendes Lernen im virtuellen Austausch. Haushalt in Bildung \& Forschung, 9(4), 24-46. https://doi.org/10.3224/hibifo.v9i4.03 
Coyle, D. (2008). CLIL - a pedagogical approach from the European perspective. In N. Van Deusen-Scholl \& N. H. Hornberger (Eds), Encyclopedia of language and education (2nd ed., pp. 97-111). Springer.

Dekker, H., \& Walsarie Wolff, S. (2016). Re-inventing research-based teaching and learning. Paper prepared for presentation at the meeting of the European Forum for Enhanced Collaboration in Teaching of the European University Association in Brussels on 5 December 2016 Belgium (p. 2). https://bit.ly/3j2kVSe

EVOLVE Project Team. (2020). The impact of virtual exchange on student learning in higher education: EVOLVE project report. https://research.rug.nl/en/publications/the-impact-of-virtual-exchange-on-student-learning-in-higher-educ

EVOLVE. (n.d.). What is virtual exchange? Evidence-Validated Online Learning through Virtual Exchange (EVOLVE). https://evolve-erasmus.eu/about-evolve/what-is-virtual-exchange/

Gaer, S. (1995). Recipes and their stories. In M. Warschauer (Ed.), Virtual connections (pp. 143-145). Hawaii University Manoa; Second Language Teaching and Curriculum Center.

Garnett, T., Mathewson, S., Angelides, P., \& Borthwick, F. (2015). Policies and actions to shift eating patterns: what works? Food Climate Research Network; Chatham House.

Geiger, S. M., Fischer, D., \& Schrader, U. (2017). Measuring what matters in sustainable consumption: an integrative framework for the selection of relevant behaviors. Sustainable Development 26, 18-33. https://doi.org/10.1002/ sd.1688

Guth, S., Helm, F., \& O’Dowd, R. (2014). Telecollaborative foreign language networks in European universities: a report on current attitudes and practices. Bellaterra Journal of Teaching \& Learning Language \& Literature, 7(4), 1-14.

Hauck, M. (2019). Virtual exchange for (critical) digital literacy skills development. European Journal of Language Policy, 11(2), 187-210. https://doi.org/10.3828/ejlp.2019.12

Hauck, M. (2020, September 15). Towards global fairness in the digital space through VE [Video]. IVEC. https:// iveconference.org/2020-conference/

Helm, F. (2015). The practices and challenges of telecollaboration in higher education in Europe. Language Learning \& Technology, 19(2), 197-217.

Huber, L., \& Reinmann, G. (2019). Vom forschungsnahen zum forschenden Lernen an Hochschulen. Springer. https://doi. org/10.1007/978-3-658-24949-6

Kramsch, C. (2014). Teaching foreign languages in an era of globalization: introduction. Modern Language Journal, 98(1), 296-311. https://doi.org/10.1111/j.1540-4781.2014.12057.x

McKenney, S. E., \& Reeves, T. C. (2019). Conducting educational design research (2nd ed.). Routledge.

Methfessel, B. (2005). Fachwissenschaftliche Konzeption: Soziokulturelle Grundlagen der Ernährungsbildung. Paderborner Schriften zur Ernährungs- und Verbraucherbildung. 7. http://www.evb-online.de/docs/07_2005-Soziokulturelle_ Grundlagen.pdf

Methfessel, B. (2006). Kultur der Nahrungszubereitung und des Essens - zwischen Handwerk und Folklore. Haushalt \& Bildung, 83(4), 3-6.

Methfessel, B., \& Schön, B. (2014). Biographisch orientierte Lehr-Lernprozesse als „Brücke“ zwischen lebensweltlichen Erfahrungen und systematischen Lehr-Lernprozessen - Erfahrungen aus einem Lehr-Forschungsprojekt. Haushalt in Bildung \& Forschung, 3(3), 91-108. 
O’Dowd, R. (2016). Learning from the past and looking to the future of online intercultural exchange. In R. O'Dowd \& T. Lewis (Eds), Online intercultural exchange: policy, pedagogy, practice (pp. 273-298). Routledge.

O’Dowd, R. (2018). From telecollaboration to virtual exchange: state-of-the-art and the role of UNICollaboration in moving forward. Journal of Virtual Exchange, 1, 1-23. https://doi.org/10.14705/rpnet.2018.jve.1

O’Dowd, R., \& Waire, P. (2009). Critical issues in telecollaborative task design. Computer Assisted Language Learning, 22(2), 173-188. https://doi.org/10.1080/09588220902778369

Pedaste, M., Mäeots, M., Siiman, L. A., de Jong, T., van Riesen, S. A. N., Kamp, E. T., Manoli, C. C., Zacharia, Z. C., \& Tsourlidaki, E. (2015). Phases of inquiry-based learning: definitions and the inquiry cycle. Educational Research Review, 14, 47-61. https://doi.org/10.1016/j.edurev.2015.02.003

Reisch, L. A., Fischer, C., GrießShammer, R., Muster, V., Schrader, U., Thorun, C., \& Wolff, F. (2020). Sustainable consumption now! The German national programme for sustainable consumption on the test bed. SSRN Electronic Journal. https://doi.org/10.2139/ssrn.3679773

Robin, B. R., \& McNeil, S. G. (2019). Digital storytelling. In R. Hobbs \& P. Mihailidis (Eds), The international encyclopedia of media literacy (vol. 2, pp. 1-8). https://doi.org/10.1002/9781118978238.ieml0056

The EVALUATE Group. (2019). Evaluating the impact of virtual exchange on initial teacher education: a European policy experiment. Research-publishing.net. https://doi.org/10.14705/rpnet.2019.29.9782490057337

UN. (2015). Transforming our world: the 2030 agenda for sustainable development. United Nations. https:// sustainabledevelopment.un.org/post2015/transformingourworld

UNICollaboration. (2014). Position paper: virtual exchange in the European higher education area. https://www. unicollaboration.org/index.php/position-papers/

Von Koerber, K., Waldenmaier, J., \& Cartsburg, M. (2020). Nutrition and the guiding principle of sustainability. Global challenges and problem-solving approaches on a national and international, UN level. Ernährungs Umschau, 67(2), 34-41. https://doi.org/10.4455/eu.2020.011

Willett, W., Rockström, J., Loken, B., Springmann, M., Lang, T., Vermeulen, S., Garnett, T., Tilman, D.,ß DeClerck, F., Wood, A., Jonell, M., Clark, M., Gordon, L. J., Fanzo, J., Hawkes, C., Zurayk, R., Rivera, J. A., Vries, W. D., Sibanda, L. M., ... Murray, C. J. L. (2019). Food in the anthropocene: the EAT-Lancet commission on healthy diets from sustainable food systems. The Lancet, 393(10170), 447-492. https://doi.org/10.1016/S0140-6736(18)31788-4 


\section{Virtual Exchange?}

Published by University of Groningen Press | UGP, a not-for-profit press

Groningen, The Netherlands | UGP@rug.nl

(C) 2021 UNICollaboration (collective work)

(c) 2021 by Authors (individual work)

Journal of Virtual Exchange 2021

Special issue edited by Carine Ullom and Müge Satar

Publication date: 2021/10/22

Journal of Virtual Exchange (JVE) is an online, open-access, peer-reviewed journal aimed at practitioners and researchers in the field known variously as virtual exchange, telecollaboration, or online intercultural exchange. It is the official journal of UNICollaboration (https://www.UNICollaboration.org/), the international academic organisation dedicated to supporting and promoting telecollaboration and virtual exchange in higher-level education.

Rights. The whole volume is published under the Attribution-NonCommercial-NoDerivatives 4.0 International licence (CC BY-NCND 4.0); individual articles may have a different licence. Under the CC BY-NC-ND licence, the volume is freely available online for anybody to read, download, copy, and redistribute provided that the author(s), editorial team, and publisher are properly cited. Commercial use and derivative works are, however, not permitted.

Disclaimer. University of Groningen Press does not take any responsibility for the content of the pages written by the authors of this article. The authors have recognised that the work described was not published before, or that it was not under consideration for publication elsewhere. While the information in this article is believed to be true and accurate on the date of its going to press, neither UniCollaboration nor University of Groningen Press can accept any legal responsibility for any errors or omissions. Additionally, the publisher makes no warranty, expressed or implied, with respect to the material contained herein. While University of Groningen Press is committed to publishing works of integrity, the words are the authors' alone.

Trademark notice. Product or corporate names may be trademarks or registered trademarks, and are used only for identification and explanation without intent to infringe.

Copyrighted material. Every effort has been made by the editorial team to trace copyright holders and to obtain their permission for the use of copyrighted material in this article. In the event of errors or omissions, please notify the publisher of any corrections that will need to by incorporated in future editions of this article.

Typeset by Research-publishing.net (https://research-publishing.net)

Noto fonts are open source. All Noto fonts are published under the SIL Open Font License, Version 1.1. Noto is a trademark of Google Inc. (https://www.google.com/get/noto/).

ISSN: 2647-4832 (online only)

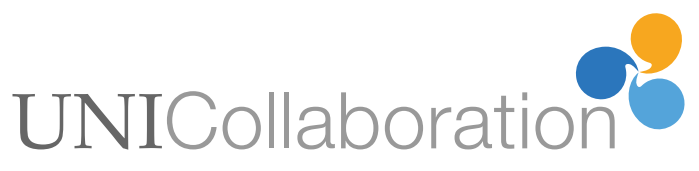

